Int. J. Electrochem. Sci., 16 (2021) Article ID: 210846

International Journal of

ELECTROCHEMICAL

SCIENCE

www.electrochemsci.org

\title{
Optimization of Environment-friendly Electrolytic Polishing of Nitinol Stent
}

\author{
Yongqi Wang, Zhiyong Li ${ }^{*}$ Xiuting Wei, Xuemin Jing, Zhikang Gong, Chuan Liu
}

Shandong University of Technology, School of Mechanical Engineering, 266 xincun west road, 255049, Zibo, China

*E-mail: lizhiyong_sdut@163.com

doi: $10.20964 / 2021.08 .48$

Received: 3 May 2021 / Accepted: 16 June 2021 / Published: 30 June 2021

Increasing number of patients with cardiovascular diseases continuously expands the market demand for stents. An environmentally friendly and nontoxic electrolytic polishing solution for stents is proposed to improve the surface quality of the laser cutting stent, eliminate slag, and recast layer. The best ratio of electrolyte is determined through experiments. On this basis, the importance of electrolytic polishing parameters was studied and optimized, and the best electrolytic polishing parameters were obtained. At the same time, the material removal rate, microscopic morphology, and surface roughness of the scaffold were investigated, and the removal rate of the bridge width and wall thickness of the scaffold was obtained. After polishing, the surface of the stent was smooth, without slag and recast layer, and the surface roughness reached approximately 10 nanometers.

Keywords: Nitinol stent; Environmentally friendly electrolyte; Electrolytic polishing parameters; Surface morphology

\section{$\underline{\text { FULL TEXT }}$}

(C) 2021 The Authors. Published by ESG (www.electrochemsci.org). This article is an open access article distributed under the terms and conditions of the Creative Commons Attribution license (http://creativecommons.org/licenses/by/4.0/). 